\title{
Monocamadas Auto-Montadas de Alcanotióis - - das Superfícies Planas à Estabilização de Nanopartículas de Ouro
}

\author{
V.C. Ferreira ${ }^{1,2}$, F. Silva ${ }^{2}$, L.M. Abrantes ${ }^{1, *}$
}

Nestin e propriedades de monocamadas auto-montadas de alcanotiois em su focando diversos factores que afectam a sua estrutura, organização e estabilidade. Releva-se - caso específico dos $\alpha, \omega$-alcanoditióis e ainda a possibilidade de utilização de superfícies com formas e tamanhos diversos, o que constitui um método geral e altamente flexível de modificação de interfaces, importante no controle da síntese, propriedades e estabilização de suspensões coloidais de nanopartículas de ouro.

\section{INTRODUÇÃO}

A organização de montagens moleculares em superfícies sólidas constitui uma forma viável de obter interfaces que, pelo controle das suas propriedades químicas e físicas (nomeadamente, composição, estrutura e espessuras) [1], são aplicáveis em diversos processos heterogéneos como a catálise, corrosão, lubrificação e adesão [1,2].

Em superfícies de ouro, as moléculas mais usadas são os alcanotióis, dialquildissulfuretos e dialquilsulfuretos, figura 1.



Figura 1 Representação esquemática de compostos orgânicos de enxofre usados na formação de monocamadas em superfícies de ouro: (a) alcanotiol, (b) dialquildissulfureto e (c) dialquilsulfureto

A auto-montagem de monocamadas de tióis em ouro deve-se à forte inte-

CQB, Departamento de Química e Bioquímica, Faculdade de Ciências da Universidade de Lisboa, Campo Grande, 1749-016 Lisboa, Portugal

CIQ-UP, Linha 4, Departamento de Química, Faculdade de Ciências da Universidade do Porto Rua do Campo Alegre 687, 4169-007 Porto, Portuga

e-mail: luisa.abrantes@fc.ul.pt racção química entre o átomo de S e a superfície [3]. A relativa simplicidade processual oculta a complexidade das interacções intermoleculares e interfaciais (tiol-substrato, grupo terminal-substrato, cadeia-cadeia e grupo terminal-grupo terminal) cujo balanço global determina a formação das monocamadas, quer cineticamente quer a nível estrutural $[4,5]$

O processo de formação e a caracterização das monocamadas auto-montadas (MC) em ouro têm sido amplamente estudados por diversas técnicas, incluindo espectroscópicas (infra-vermelho (IV) [1,6-16], Raman [17-20], fotoelectrões de raios-X (XPS) [10-13,16,21-31], de difracção (raios-X (DRX) [21,32,33], electrões [34] e átomos de hélio [5,31,35-37]), electroquímicas (voltametria cíclica (CV) [1,6-8, 10,15,21,28,38-49], espectroscopia de impedância electroquímica (EIS) [15,47-50], microbalança electroquímica de cristal de quartzo (EQCM) [46,51,52]), microscópicas (força atómica (AFM) [20,23,29,49,53-56], varrimento por efeito de túnel (STM) $[3,5,21,38,47,48,53,57-65])$, medidas de ângulo de contacto [6,23-25,50] e elipsometria [1,19,22,23,25,34].

Em resultado dos desenvolvimentos verificados e conhecimento adquirido surge a possibilidade de estabilizar nanopartículas de ouro (Au-NPs) com tióis, adicionando estes no passo de síntese ou por reacção de substituição de ligandos após a preparação das suspensões coloidais, o que permite a obtenção de estruturas complexas funcionalizadas com interesse e aplicabilidade no domínio das nanociências e nanotecnologias.

\section{Organização e Estabilidade das Monocamadas Auto-Montadas}

Em geral, um filme cristalino só pode ser obtido à temperatura ambiente se as interacções atractivas entre as cadeias alquilo, devido às forças de van der Waals, forem suficientemente fortes para as alinhar de modo paralelo [3]. Assim, dependendo do comprimento das cadeias, as MC podem variar de altamente densas e de fase tipo-cristalina (para cadeias longas, $n \geq 10$ ) a pouco densas e parcialmente desordenadas (com cadeias curtas) [1,3,41]. Com a diminuição do comprimento da cadeia alquilo decresce a energia total das interacções atractivas entre cadeias, a cobertura superficial e a ordem intra- e intercadeia; neste caso, as moléculas adsorvidas em locais da superfície menos energéticos são mais susceptíveis de apresentarem desordem térmica [1]

Os $n$-alcanotióis $\left(\mathrm{C}_{\mathrm{n}}-\mathrm{SH}\right.$, grupo terminal $-\mathrm{CH}_{3}$ ) formam monocamadas com distintas periodicidades em diferentes superfícies de ouro. Diversas técnicas, como difracção de átomos de $\mathrm{He}$, electrões e raios- $X$, têm permitido assumir que o $S$ do tiol se liga à superfície de ouro, formando um tiolato, RS-Au(I) [26,32,33,45], numa camada 
com arranjo comensurável com uma estrutura $(\sqrt{ } 3 \times \sqrt{ } 3) R 30^{\circ}[3,6,9,34]^{1}$; crê-se que ocorre adsorção nos locais em que o átomo de $\mathrm{S}$ (com hibridização $s p^{3}$ ) coordena com 3 de Au (triple hollow sites) da superfície $\mathrm{Au}(111)$ e removem a reconstrução $(\sqrt{3} 322)[66]^{2}$. Nesta superfície, os grupos metilo terminais formam domínios com um arranjo hexagonal e uma periodicidade constante de 5,01 $\pm 0,02 \AA[3,6,9,34]$. Simulações moleculares [67], espectroscopia de IV $[1,6,11]$, difracção de raios-X $[32,33]$ e de electrões [34] sugerem que as cadeias das moléculas estão inclinadas cerca de $28-40^{\circ} \mathrm{em}$ relação à normal com a superfície. $\mathrm{Na}$ figura 2 encontra-se uma representação esquemática da coordenação dos átomos de $\mathrm{S}$ nas superfícies $\mathrm{Au}(111)$, $A u(110)$ e $A u(100)$. Os parâmetros da célula unitária para o $n$-alcanotiol adsorvido em $\mathrm{Au}(110)$ sugerem que os átomos de $\mathrm{S}$ quimicamente adsorvidos removem a reconstrução $(1 \times 2)$ da superfície $\mathrm{Au}(110)$ (missing row reconstruction) e formam um arranjo comensurável com uma estrutura $c(2 \times 2)^{3}$ coordenando com 4 átomos de $\mathrm{Au}$ da superfície. A adsorção em $\mathrm{Au}(100)$ apresenta um padrão mais complexo com 4 tipos de domínios equivalentes, devido à sua simetria (fourfold symmetry), e incomensurável com a estrutura da superfície [36]. Este facto confirma a elevada importância que as interacções substrato-enxofre têm na determinação da periodicidade e densidade de empacotamento das moléculas na monocamada.



tivamente, reflectindo as diferentes energias de ligação ao substrato. No entanto, outros autores obtiveram em superfícies $A u(111)$, valores entre 5,0-

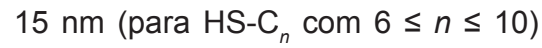
[59] e de $\approx 32 \mathrm{~nm}(n=18)$ [68] e fronteiras com largura de cerca de 0,2 a $0,3 \mathrm{~nm}$ [41], confirmando o aumento esperado do tamanho dos domínios com o comprimento da cadeia alquilo. Depressões típicas nas MC de $n$-alcanotióis (e ditióis - HS- $\mathrm{C}_{n}-\mathrm{SH}$ ), analisadas por STM, apresentam uma profundidade de cerca de 0,24 nm, diâmetro médio de 2-5 nm e embora sejam observadas para diferentes comprimentos de cadeia ( $n=3-18$ ), são mais numerosas em monocamadas de $n$-alcanotióis de cadeia longa $[3,53,60]$. Imagens de STM de escala atómica revelam a presença de uma camada ordenada nesses locais [3,53]. McDermott et al. [53] e Esplandiu et al. [48] sugerem que estas têm origem na superfície do substrato de ouro e não na estrutura da MC e que têm por base processos de reconstrução, com compressão na superfície de ouro devido à nucleação e agregação de moléculas [53] e à mobilidade dos átomos de ouro da superfície sob a monocamada, aumentada pela formação do tiolato RS-Au(I) [48,57]. Este efeito é ainda corroborado pela detecção de ouro na solução de formação da MC [57,60]; depressões nas fronteiras de domínio e ausência delas em superfícies com terraços de pequenas dimensões suportam o mecanismo proposto [53].



ção, com baixo grau de recobrimento [59] e após tratamento térmico [35].

\section{Estudos por EQCM sugerem} a possibilidade de formação de mono- e multi-camadas de HS- $\mathrm{C}_{n}$, dependendo do tempo de imersão e solvente usado. Kim et al. [70] verificaram que em solução etanólica, para $t>24 \mathrm{~h}$, ocorre a formação de multicamadas de 1-octadecanotiol e Schneider et al. [51] reportaram que, sob um potencial de adsorção aplicado e em acetonitrilo (ACN), ocorre a formação de multicamadas $\left(\mathrm{CH}_{3}\left(\mathrm{CH}_{2}\right)_{9} \mathrm{SH}\right.$ e $\left.\mathrm{CH}_{3}\left(\mathrm{CH}_{2}\right)_{11} \mathrm{SH}\right)$, com uma cinética de adsorção rápida; em dimetilformamida (DMF) a cinética de adsorção é lenta, não tendo sido observada a formação de multicamadas. A informação obtida por EQCM encontra-se em concordância com outros estudos cinéticos realizados por Bain et al. [25] , usando elipsometria e medidas de ângulo de contacto. Estes autores verificaram que a formação de MC de HS-C ${ }_{n}$, sem aplicação de potencial, em solução etanólica é sensível ao comprimento da cadeia alquilo (aumenta com $n$ ), concentração de tiol, tipo de solvente e exibe uma cinética bifásica (adsorção rápida de uma camada imperfeita seguida por um processo de adsorção adicional e consolidação), envolvendo possivelmente o deslocamento de contaminantes, expulsão de solvente e difusão lateral na superfície para reduzir os defeitos e aumentar o empacotamento.

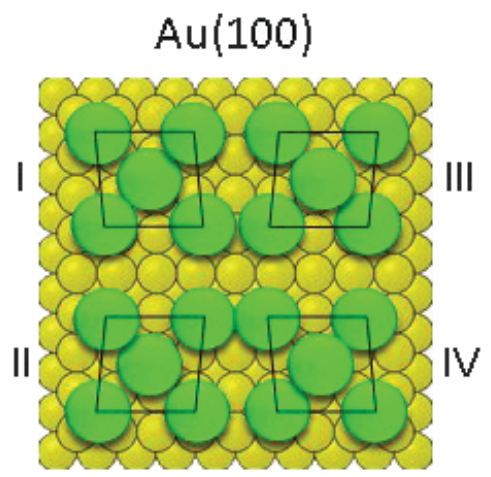

Figura 2 Representação esquemática da coordenação dos átomos de S nas superfícies $\mathrm{Au}(111), \mathrm{Au}(110)$ e $\mathrm{Au}(100)$. Adaptada com permissão da referência [36]. Copyright 1993, American Institute of Physics.

Camillone et al. [36] estimaram o tamanho médio dos domínios formados pelos grupos metílicos terminais de $\mathrm{CH}_{3}\left(\mathrm{CH}_{2}\right)_{21} \mathrm{SH}$ auto-montado nas faces $\mathrm{Au}(111), \mathrm{Au}(110)$ e $\mathrm{Au}(100) \mathrm{em}$ cerca de $22,8,38,6$ e $23,4 \AA$, respec-
De salientar que podem ser obtidas diferentes estruturas quando as monocamadas são depositadas por feixes moleculares [36], deposição em fase de vapor [69], MC de alcanotióis de cadeia curta, preparadas em solu-
Técnicas electroquímicas, como voltametria cíclica [45] e EQCM [46,51,52], permitem determinar a cobertura superficial de MC formadas pela adsorção química de tióis em Au. De acordo com o reportado por Porter e co-auto- 
res $[9,45]$ a desadsorção de tióis deve ocorrer em meio alcalino $(\mathrm{pH}>11)$, por um processo oxidativo envolvendo 3 electrões (reacção 1) ou redutivo envolvendo 1 electrão (reacção 2).

$\mathrm{Au}(\mathrm{I})-\mathrm{SR}+2 \mathrm{H}_{2} \mathrm{O} \rightarrow \mathrm{Au}(0)+\mathrm{RSO}_{2}^{-}+$ $+4 \mathrm{H}^{+}+3 \mathrm{e}$ Reacção 1

$\mathrm{Au}(\mathrm{I})-\mathrm{SR}+1 \mathrm{e}^{-} \rightarrow \mathrm{Au}(0)+\mathrm{RS}^{-}$

Reacção 2

A carga eléctrica envolvida na desadsorção redutiva, $Q_{\mathrm{RS}-\mathrm{Au}(1)}$, de uma monocamada de alcanotiolato (depois de considerada a rugosidade superficial e de acordo com as descrições estruturais - cadeias densamente empacotadas com uma inclinação média de $30^{\circ}$ em relação à normal com a superfície) com recobrimento de saturação numa estrutura $(\sqrt{3} x \sqrt{3})$ $\mathrm{R} 30^{\circ} \mathrm{em} \mathrm{Au}(111)$ é de $\approx 70-85 \mu \mathrm{C} \mathrm{cm}^{-2}$ $[9,28,34,37,41,45,47,48,58]$.

O recobrimento superficial, $\Gamma_{\mathrm{RS}-\mathrm{Au}(\mathrm{l}) \text {, }}$ é determinado através da carga $\left(Q_{\text {RS-Au(I) }}\right)$ envolvida na reacção 2, usando a relação 1 :

$\Gamma_{\mathrm{RS}-\mathrm{Au}(\mathrm{l})}=\mathrm{Q}_{\mathrm{RS}-\mathrm{Au}(\mathrm{I})} / \mathrm{n} F A$

onde $\mathrm{n}$ é o número de electrões envolvidos na reacção $2, F$ a constante de Faraday $\left(F=96485 \mathrm{C} \mathrm{mol}^{-1}\right)$ e $A$ a área geométrica do eléctrodo de ouro. Valores típicos de $\Gamma_{\mathrm{RS}-\mathrm{Au}(\mathrm{I})}=7,6 \times 10^{-10}$ mol cm$~^{-2}$ têm sido reportados para HS$\mathrm{C}_{n}(n>10)[7-9,21,34,37,47,48,62,65]$. MC formadas a partir de alcanotióis de cadeia mais curta $(n \leq 10)$ podem apresentar valores de recobrimento superficial ligeiramente inferiores, provavelmente em consequência da menor organização da MC, como se ilustra na figura 3 para o 1-decanotiol, com valores de $\Gamma \approx 6,8 \times 10^{-10} \mathrm{~mol} \mathrm{~cm}^{-2}$.

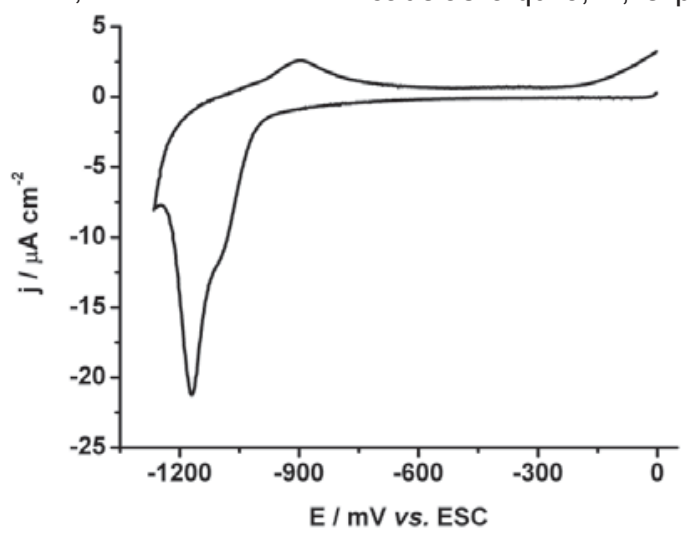

Figura 3 Voltamograma cíclico obtido durante a desadsorção redutiva de uma monocamad formada a partir de 1-decanotiol (solução etanólica) em $\mathrm{Au}(111) ; \mathrm{NaOH} \mathrm{0,1} \mathrm{mol} \mathrm{dm}{ }^{-3}$. velocidade de varrimento $v=20 \mathrm{mV} \mathrm{s}^{-1}$

Embora, a partir de resultados de EQCM, Schneider et al. [51] tenham sugerido que o número de electrões envolvidos na desadsorção redutiva de MC de HS- $C_{n}$ é $n \neq 1$, outros autores $[9,71]$ verificaram a relação estequiométrica apresentada na reacção 2 ( $n=$ =1) por comparação entre as cargas envolvidas na desadsorção redutiva e na conversão redox em monocamadas auto-montadas de tióis contendo grupos terminais electroactivos (como os ferrocenos, $\mathrm{FcC}_{n} \mathrm{~S} ; n=6$, 8 e 10, que apresentam um comportamento típico de um par redox ligado à superfície, $\mathrm{j}_{\mathrm{p}} \propto \mathrm{v}$ ) ou através da variação de massa observada por EQCM e a carga envolvida na desadsorção redutiva de MC de alcanotióis [46,51]. Discrepâncias entre os valores de recobrimento superficial obtidos a partir da carga envolvida na desadsorção redutiva $\left(\Gamma_{\mathrm{Q}}\right)$ e da variação de massa registada por EQCM $\left(\Gamma_{\Delta \mathrm{m}}\right)$ foram observadas por diversos autores $[46,51]\left(\Gamma_{Q}\right.$ $\left.>\Gamma_{\Delta \mathrm{m}}\right)$. Schneider et al. [51] sugerem que essas diferenças possam estar relacionadas com factores que afectam a carga da dupla camada, $Q_{d l}$ (por ex. $Q_{d l}$ aumenta com a densidade de defeitos e diminui com o comprimento da cadeia alquilo do tiol), e com a complexidade da ligação Au-S, nomeadamente com o número de electrões $(n \neq 1)$ requeridos para a desadsorção redutiva de tióis de superfícies de Au. No entanto, será também necessário ter em conta processos de transporte de massa, nomeadamente a adsorção de catiões do electrólito após desadsorção do tiol, como reportado por Kawaguchi et al. [46].

Os perfis voltamétricos são fortemente influenciados pelo comprimento das cadeias alquilo, $n$, e pela orientação 
camente planas $\mathrm{Au}(111)$, apresentam um único pico de desadsorção redutiva. Este é deslocado para valores de potencial mais negativos nas superfícies de Au monocristalinas na ordem (110) > (111) em cerca de 200-300 mV [10] (reflectindo a diferença de energia de ligação do tiol - com igual $n$ - nos substratos de $\mathrm{Au}$ ) e com o aumento do comprimento das cadeias alquilo em cerca de $20 \mathrm{mV} /$ grupo $\mathrm{CH}_{2}$ (devido ao aumento das interacções coesivas entre as cadeias) $[1,41,45,73]$. Um desdobramento do pico de desadsorção é, ainda, frequentemente observado. Em superfícies com características morfológicas distintas a nível microscópico, como a densidade de degraus $(\mathrm{Au} / \mathrm{Si} \approx \mathrm{Au} / \mathrm{vidro}>\mathrm{Au} / \mathrm{mica})$, a separação dos picos (200-300 mV) reflecte as dissemelhantes energias de ligação do $S$ ao substrato $[10,21]$. Em $n$-alcanotióis de cadeia longa, a separação de cerca de 20-100 mV [41], revela diferenças de empacotamento das cadeias alquilo com domínios moleculares de distintas ordens estruturais e tamanhos e transições de fase ordem-desordem (por analogia com o observado na redissolução de $\mathrm{Pb}$ a sub-potencial em $A u(111)$, seriam de esperar separações entre os picos na ordem de 30-50 mV [21]). Imagens de STM, onde se observaram domínios ordenados entre 2-20 nm e fronteiras com largura de cerca de 0,2 a 0,3 nm (dimensões médias dos domínios devem aumentar com o comprimento das cadeias alquilo), corroboram esta possibilidade $[3,30,53,59]$.

\section{TransferênCIa Electrónica atra- VÉS DE Monocamadas}

Tem sido sugerido que a transferência electrónica (TE) através de monoca-
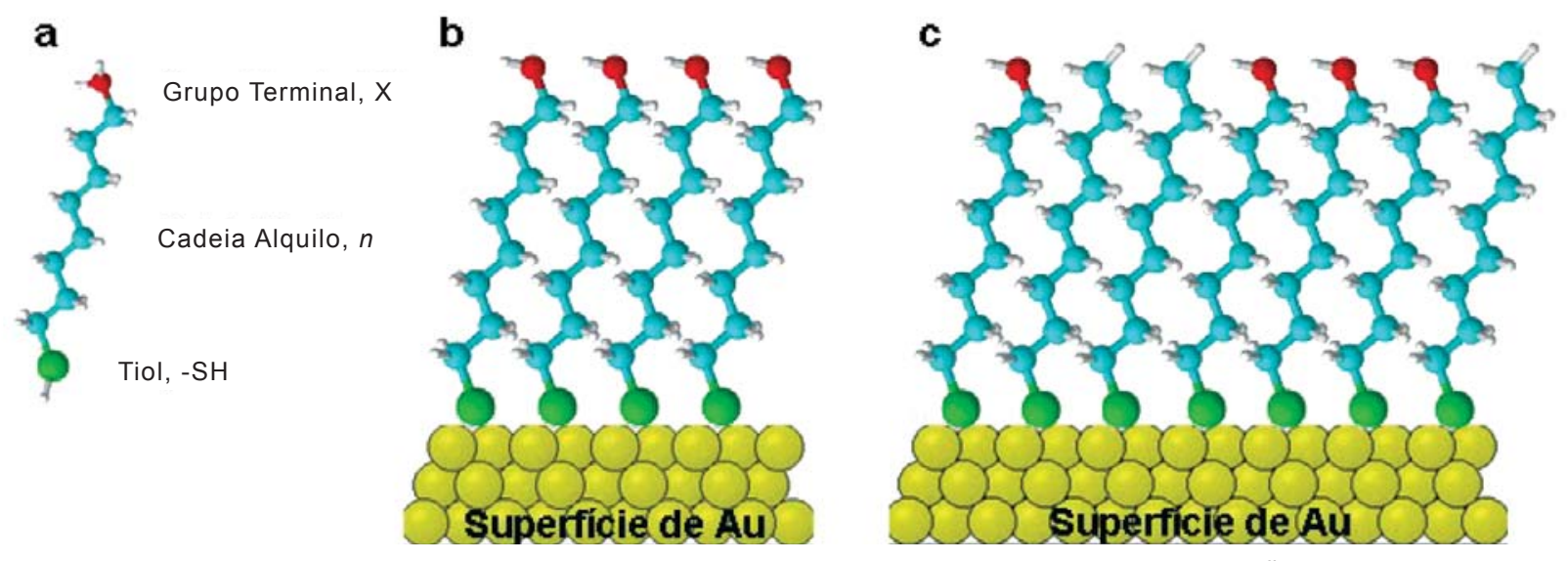

Segundo Oevering et al. [74] há evidência de TE, por efeito de túnel, numa escala de tempo de ns, em monocamadas (20 a $30 \AA$ de espessura) de ácidos gordos (fosfolípidos) em filmes de Langmuir-Blodgett. Estudos electroquímicos demonstram que MC de $n$-alcanotióis de cadeia longa são consideravelmente impermeáveis a iões [6]. Em superfícies policristalinas de ouro onde aquelas são bem organizadas [49], constituem-se como barreiras de alta qualidade aos processos de TE e iónica. No entanto, podem existir defeitos nestas estruturas, nomeadamente devidos a facetamento cristalográfico, rugosidade superficial, complexidade da ligação S-Au e desvios dos parâmetros de malha ideais para o empacotamento das cadeias alquilo e grupos ligados ao substrato. As cadeias mais curtas promovem a perda de organização dos filmes, do que resulta uma diminuição da densidade de empacotamento e o início de permeabilidade a iões da solução [1].

\section{$\omega$-Alcanotióls e Monocamadas FunCIONALIZADAS}

A elevada força de ligação dos tióis ao Au, acima referida, permite a construção de monocamadas com propriedades específicas, seleccionando $\omega$-alcanotióis com diferentes grupos terminais $\left(\mathrm{X}-\left(\mathrm{CH}_{2}\right)_{n}-\mathrm{SH}, \mathrm{X}=\right.$ $\mathrm{OH}, \mathrm{NH}_{2}, \mathrm{CO}_{2} \mathrm{H}$, SH, etc.) $[6,11,25]$ ou formando $M C$ mistas de diferentes tióis [12,26,75,76], figura 4.
As MC de tióis funcionalizados são relevantes no estudo de processos interfaciais tais como adesão, humedecimento, reconhecimento molecular e em dispositivos electrónicos moleculares. Questões relacionadas com a perturbação do empacotamento denso das cadeias de polimetileno pelos grupos terminais grandes (cujo tamanho afecta o espaçamento entre cadeias, podendo inclusivamente inserir desordem) ou com a natureza das interacções direccionais mais fortes do que o grupo $-\mathrm{CH}_{3}$ (por ex. ligações de hidrogénio) são de fundamental importância [6].

As monocamadas mistas podem ser preparadas por deposição simultânea $[12,24,26,43,44,75-77]$ ou sequencial $[24,57]$ dos seus componentes. No primeiro caso, a composição da MC é determinada pelas propriedades das moléculas, como comprimento da cadeia, grupo terminal e solubilidade (o tiol menos solúvel é depositado preferencialmente; comprimentos de cadeia semelhantes permitem obter uma MC mista mais homogénea), fracção molar de cada componente e concentração, identidade e temperatura do solvente e tempo de deposição [12,24,26,43,75-77]. Por exemplo, na preparação de MC mistas de tióis contendo os grupos terminais $-\mathrm{CH}_{3} \mathrm{e}$ - $\mathrm{OH}$, a adsorção do primeiro é favorecida em relação ao segundo, o que pode estar relacionado com a formação de ligações de hidrogénio fracas entre os grupos -OH numa superfície rica em grupos metilo [26]. Alguns estudos sugerem que pode ocorrer a segregação de componentes da MC em domínios discretos [12,44,75,77], especialmente quando o comprimento das cadeias é muito diferente ou os

Figura 4 Esquema de monocamadas de (a) $\omega$-alcanotiol e (b) mista ( $n$-alcanotiol / $\omega$-alcanotiol) em superfícies de Au 
tióis apresentam características distintas, como exemplificado na figura 5 .

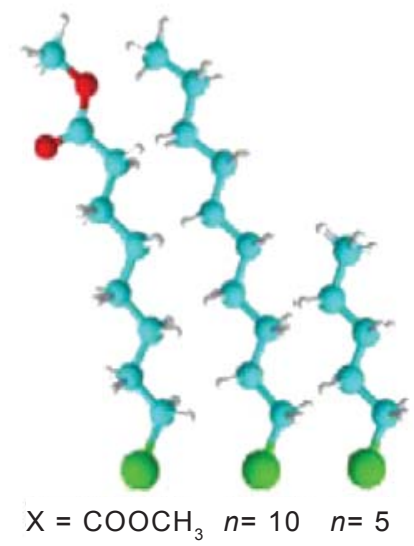

Figura 5 Alcanotióis com diferentes grupos funcionais (- $\mathrm{COOCH}_{3}$ e $-\mathrm{CH}_{3}$ ) e comprimentos de cadeia alquilo $(5,7$ e 10$)$

Phong et al. [77] reportaram a formação de monocamadas auto-montadas constituídas por 3 componentes, exibindo domínios distintos constituídos por zonas de composição mista contendo AET-MES (AET = 2-aminoetanotiol; MES = ácido 2-mercaptoetano-sulfónico, hidrofílicos e cujas interacções electrostáticas parecem favorecer a sua formação) e outras compostas de 1-dodecanotiol (hidrofóbico); verificaram que a formação, composição e predominância de cada um dos domínios depende da concentração inicial de cada tiol na solução de formação e do tempo de imersão. Esta abordagem constitui um modo simples de preparação de superfícies modificadas padronizadas, em alternativa à padronização por microcontacto [77]. Na deposição sequencial, o segundo componente é incorporado numa MC pré-existente, por imersão do substrato noutra solução de deposição [24,57].

\section{O CASO PARTICULAR DOS $\alpha, \omega$-ALCANODITIÓIS}

De entre os alcanotióis $\omega$-substituídos, os alcanoditióis com um grupo termi- nal -SH ( $\alpha, \omega$-alcanoditióis, HS-C $-\mathrm{SH})$ têm vindo a ganhar considerável interesse, devido à sua potencialidade na construção de nanodispositivos. Com efeito, os grupos -SH no topo de cadeias hidrocarbonadas oferecem a possibilidade de ligação com outras unidades funcionais [56] para o desenvolvimento de estruturas complexas (por exemplo, metal/isolador/metal, multicamadas com catiões metálicos $[22,23]$ ou nanopartículas incorporadas entre camadas $[13,48,78])$. Na última década, muito se tem publicado acerca da estrutura de monocamadas auto-montadas de $\alpha, \omega$-alcanoditióis $[56,79]$. No entanto, não tem havido consenso quanto ao modo de ligação dos ditióis à superfície [56]; devido à existência de um grupo tiol em cada extremidade, ela pode ocorrer por apenas um ou ambos os grupos -SH [14], como se ilustra na figura 6-a e b.
[79] . Diversos estudos mostram que a formação de $M C$ de ditióis não origina camadas ordenadas, enquanto outros indicam o contrário $[5,56,79]$. As condições experimentais de auto-montagem parecem ser determinantes da estrutura das monocamadas de ditiol; estas poderão adoptar desde uma configuração (i) estendida e paralela à superfície [5], a (ii) uma orientação vertical com diferentes ângulos de inclinação em relação à normal com a superfície [16-18,27], figura 6-a e c. A obtenção de estruturas organizadas tem sido possível apenas para MC preparadas a partir de fase gasosa $[5,80]$, de solução após aquecimento [5], sob potencial aplicado $[47,48]$ ou para $\alpha, \omega$-alcanoditióis de cadeia longa após longos períodos de imersão [80]. A partir de fase gasosa e para baixos graus de recobrimento é geralmente obtida uma fase pouco densa,

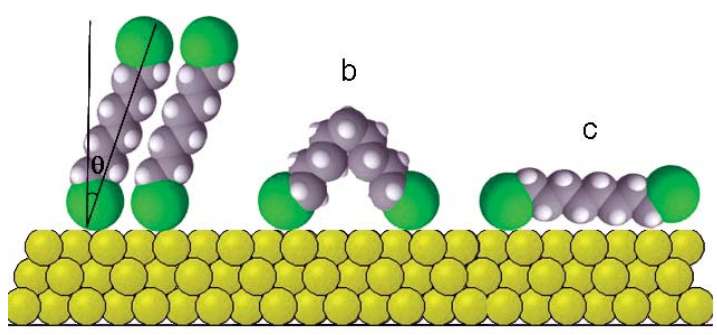

Figura 6 Representação esquemática de possíveis orientações das moléculas de ditiol na superfície de $\mathrm{Au}$; (a) perpendicular ou formando um ângulo $\theta$ em relação à normal com a superfície (ligação por apenas um grupo - $\mathrm{SH}$ ), (b) formação de aselha e (c) estendida e paralela
à superficie (ligação por ambos os grupos - SH, b e c)

Brust et al. [22] verificaram por elipsometria que tanto o 1,6-hexanoditiol como o 1,9-nonanoditiol formam MC com a espessura esperada para este tipo de moléculas, em solução de 2-propanol. Os resultados sugerem que a ligação de ambos os grupos tiol à superfície não ocorre, à semelhança do reportado por Nakamura et al. [63] para o 1,12-dodecanoditiol e outros $\alpha, \omega$-alcanoditióis, embora simulações moleculares indiciem que a probabilidade de formação de aselhas (loops) aumenta para alcanoditióis com $n>8$ com configuração paralela à superfície, conferindo um aspecto listrado às imagens de STM [81], como se ilustra na figura 7 .

Tem sido geralmente aceite que a auto-montagem é composta por dois passos consecutivos, adsorção rápida e não orientada, seguida de ordenamento e empacotamento conformacional das moléculas em MC bem organizadas $[25,47,48]$.
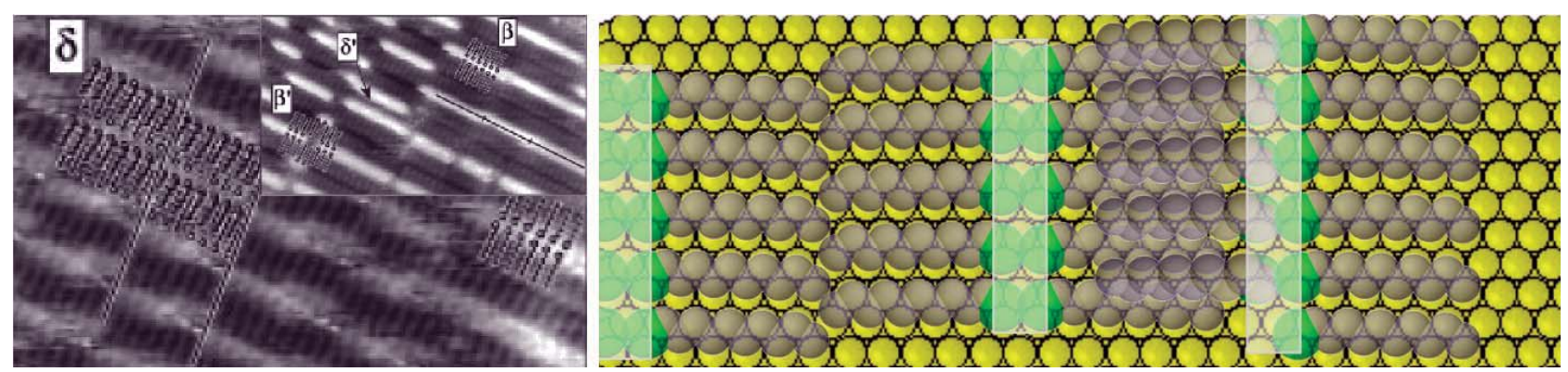

Figura 7 (a) Imagem de STM de MC de decanotiol em Au e (b) representação esquemática do arranjo e orientação das moléculas adsorvidas na superfície Au(111). Reproduzida com permissão da referência [81]. Copyright (1999), American Chemical Society 
Também tem sido demonstrado que, durante a exposição prolongada de $n$-alcanotióis com diferentes grupos funcionais terminais (por ex. $-\mathrm{OH}$ ), ocorre uma transição entre uma fase com as moléculas paralelas à superfície e outra com as cadeias alquilo orientadas perpendicularmente a esta $[5,82]$. No caso dos $\alpha, \omega$-alcanoditióis, estudos por CV e STM in situ mostram efectivamente que a desadsorção redutiva do 1,8-octanoditiol é caracterizada pela transição entre uma $\mathrm{MC}$ compacta, com configuração molecular perpendicular à superfície, e outra, menos densa, com as moléculas de ditiol orientadas paralelamente, enquanto que no processo de readsorção oxidativa a superfície é inicialmente recoberta pela fase menos densa até que a transição para uma fase compacta ocorre $[47,48]$. No método mais comum de preparação de MC (montagem em solução) ambas as conformações (perpendicular e paralela à superfície) são possíveis [56]. Apesar da dificuldade em obter imagens por STM das monocamadas de $\alpha, \omega$-alcanoditióis, em que vários processos podem concorrer para a falta de estrutura $[22,47,48,55]$ (interacções ponta-amostra, responsáveis pela alteração local da MC na sua proximidade, distribuição aleatória de ligações dissulfureto na interface MC/ /electrólito ou a ausência efectiva de ordem), depressões típicas do substrato de $A u$ induzidas pelo tiol são visíveis em imagens de monocamadas, recém preparadas, de 1,8-octanoditiol em superfície de $\mathrm{Au}(111)$, obtidas a partir de solução etanólica $[47,48]$. A falta de domínios com estrutura bem definida, também observada para o 1,6-hexanoditiol em Au(111) [5,48] indica que, para estes tamanhos de cadeia, não é possível obter fases cristalinas (apenas após aquecimento [5]); e que em geral, as MC de alcanoditióis, preparadas por imersão, não apresentam estruturas bem definidas. Embora os $\alpha, \omega$-alcanoditióis nem sempre permitam obter MC organizadas, a possibilidade de formar ligações dissulfureto (intracamada ou intercamadas) [16-19,56], multicamadas de ditióis ou com iões metálicos, nanopartículas e filmes finos metálicos [22,23,28,29,55,78,83-87] ou sofrer oxidação [27,88], sugere uma forte tendência para as moléculas de ditiol manterem um dos seus grupos tiol livre. Evidência da formação de ligações dissulfureto pode ser obtida de resultados da desadsorção redutiva; o deslocamento do potencial de desadsorção do ditiol no sentido dos potenciais mais negativos, em relação ao monotiol, indica que a monocamada do primeiro apresenta maior estabilidade do que a de monotiol. Esse aumento tem sido atribuído à presença de ligações dissulfureto na MC entre átomos de $S$ terminais $[47,48]$. Para além do deslocamento de potencial, cargas envolvidas nos picos de desadsorção redutiva e readsorção do ditiol $\left(109 \mu \mathrm{C} \mathrm{cm}\right.$ cm $^{-2}$ e $\mu \mathrm{C} \mathrm{cm}^{-2}$, respectivamente) superiores às reportadas para os $n$-alcanotióis $\left(Q_{\text {desad. }}=85\right.$ $\mu \mathrm{C} \mathrm{cm}{ }^{-2}$ para $4 \leq n \leq 16$, e $Q_{\text {reads. }}=25$ $\mu \mathrm{C} \mathrm{cm} \mathrm{cm}^{-2}$ para $4 \leq n \leq 11$, para um recobrimento superficial de 0,33 no caso de um electrão transferido por molécula de tiolato) têm sido atribuídas à redução de ligações dissulfureto, em simultâneo com o processo de desadsorção redutiva [47]. Se as moléculas de ditiol (por ex. 1,8-octanoditiol) estivessem orientadas paralelamente à superfície, o recobrimento seria 0,10 e a carga de redução deveria ser cerca de $50 \mu \mathrm{C} \mathrm{cm}^{-2}$, considerando que estão envolvidos dois electrões por molécula de ditiol [47].

Quanto às multicamadas de ditióis, estas podem formar-se em ouro, tanto a partir de compostos alifáticos como aromáticos, através de ligações S-S intermoleculares $[16,17,19]$. Kohli et al. [16] e Joo et al. [18] reportaram, com base em estudos por elipsometria, que $\alpha, \omega$-alcanoditióis em ouro se organizam em estruturas até 8 a 9 camadas ligadas covalentemente (através de uma reacção oxidativa com a formação de uma ligação dissulfureto). No entanto, Rieley et al. [27] e Nakanishi et al. [13], usando solução etanólica e baseando-se em resultados de XPS, sugerem que ditióis $\left(\mathrm{HS}-\mathrm{C}_{n}-\mathrm{SH}\right.$, $n=6,8$ e 10) formam MC em ouro. Assim, a formação de multicamadas e a consequente espessura da camada adsorvida é dependente do tipo de solvente. Joo et al. [18] verificaram, por elipsometria, que em superfícies de ouro o 1,3-propanoditiol forma 1 a 1,5 camadas em solventes polares e próticos (metanol) enquanto que em n-hexano forma 3 multicamadas. Por outro lado, embora as ligações dissulfureto não ocorram rapidamente em solução, podem formar-se facilmente uma vez que o ditiol se ligue à superfície sólida devido, presumivelmente, a uma diminuição da barreira de activação do processo.

Brust et al. [22] verificaram que após formação da monocamada os grupos tiol livres na interface MC/solução sofrem oxidação a dissulfureto; esta oxidação pode permitir a redução de iões $\mathrm{Cu}(\mathrm{II})$ a $\mathrm{Cu}(\mathrm{I})$ que, ficando ligados à superfície, possibilitam a auto-montagem de camadas sucessivas de ditiol e iões cobre [22]. O mesmo também se verifica para a prata [23], reforçando que a ligação do ditiol à superfície se dá apenas através de um dos grupos tiol da molécula.

Monocamadas de ditióis têm também sido usadas para imobilizar partículas metálicas na superfície, tanto a partir de suspensões [78,83-86] ou por deposição por vapor [28,29,55,87], como através da redução de iões metálicos pré-adsorvidos no topo de MCs (que apresentem grupos funcionais terminais adequados), originando camadas metálicas ou partículas submicron na interface MC/solução [22,23,28]. Enquanto que Au ou Ag, depositados por vapor, penetram nas monocamadas de alcanotióis e ficam inseridos na interface substrato (Au)/MC [55,89-92], a deposição daqueles metais em monocamadas de alcanoditióis (com o grupo terminal tiol orientado para a interface MC/ar), origina nanopartículas metálicas no topo da monocamada $[28,29,55,87]$ devido à forte interacção com os grupos tiol disponíveis. A forte interacção de ouro com o átomo de $S$ de moléculas de ditiol em $\mathrm{Au}(111)$ parece suprimir efectivamente a penetração de átomos de Au depositados, através da camada de ditiol e resulta na formação de nanoagregados homogéneos de Au [29].

A electrodeposição metálica sobre as monocamadas é outra abordagem possível. Tem-se verificado que os locais de defeito da MC actuam como pontos preferenciais de nucleação e que a existência de iões metálicos em solução permite a sua penetração na MC e deposição directa na superfície do substrato $[28,48]$. 
Estudos por XPS mostraram de forma inequívoca o alinhamento do 1,8-octanoditiol adsorvido na superfície de ouro. Foi detectada a presença de dois tipos de átomos de $S$ não equivalentes, consistentes com a estrutura em que um dos átomos está ligado directamente ao substrato na interface Au/MC e o outro numa posição afastada da superfície, na interface MC/ar [27]. No que respeita à oxidação dos grupos tiol afastados da superfície, tem também sido referido $[93,94]$ que, quando expostas à luz ambiente do laboratório $(\lambda>400 \mathrm{~nm})$ e na presença de oxigénio, ocorre a foto-oxidação do $\mathrm{S}(\mathrm{II})$ a $\mathrm{S}(\mathrm{VI})$, embora após 3h de exposição não se detecte oxidação na interface Au/MC [27]. Estas observações estão de acordo com o modelo de Laibinis e Whitesides [2], em que a monocamada bloqueia o acesso de oxigénio à superfície metálica. A fotooxidação é selectiva e deve envolver a transferência de electrões do metal para o grupo tiol (afastado da superfície) seguida pela reacção com oxigénio (com formação de grupos sulfonato $\left.-\mathrm{SO}_{3} \mathrm{H}\right)$ [27].

Registam-se diversas abordagens para obter MC de alcanoditióis ligados à superfície por apenas um dos seus grupos tiol. (i) A imersão simples de substrato de Au em solução etanólica contendo o ditiol, sob ambiente de $\mathrm{N}_{2}$ e por longos períodos (36 h), permite, segundo Yang et al. [86], obter monocamadas de 1,6-hexanoditiol e 1,9-nonanoditiol compactas e organizadas, onde a transferência electrónica para uma espécie electroactiva $\left(\mathrm{Fe}(\mathrm{CN})_{6}{ }^{3-}\right)$ em solução é totalmente bloqueada. A disponibilidade dos grupos tiol terminais nestas monocamadas, permitiu imobilizar com sucesso Au-NPs (através da interacção entre o - $\mathrm{SH}$ livre da MC e a superfície de Au da partícula). (ii) A adsorção a uma temperatura mais elevada do que a ambiente $\left(55^{\circ} \mathrm{C}\right)$, utilizada por Ohgi et al. [55] na obtenção de MC de alcanoditióis ( $n=6,8$ e 10) organizadas e com um dos grupos tiol livre orientado para a solução, mostrou que se formam maiores áreas densamente empacotadas do que as observadas no processo conduzido à temperatura ambiente em que, na maior parte da superfície, são observadas estruturas com as moléculas orientadas parale- lamente à superfície. (iii) $\mathrm{O}$ método desenvolvido por Meshulam et al. [14], que consiste na substituição de moléculas de amoníaco fracamente adsorvidas na superfície de ouro por alcanoditióis; a presença de amoníaco desfavorecendo a adsorção do segundo grupo tiol e consequentemente a formação de aselhas, facilita a formação de MC de alcanoditióis organizadas [14]. (iv) A co-adsorção de ditióis e monotióis, para conseguir mono camadas auto-montadas densamente empacotadas e orientadas mais verticalmente do que as obtidas apenas a partir dos ditióis [64]. (v) A inserção de ditióis após formação de uma MC de tiol, permitindo que aquela ocorra preferencialmente em locais de defeito da monocamada original, tal como para o 1,10-decanoditiol [57]. (vi) A utilização de ditióis com um dos grupos protegidos, seguida da remoção dessa protecção; no entanto, a disponibilidade comercial de tais ditióis é limitada. (vii) A adição de antioxidantes à solução (por ex. tris- $n$-butilfosfina $[56,95]$ ), para impedir a formação de multicamadas magnéticas, electrónicas e químicas singulares que diferem significativamente das dos materiais macroscópicos $[98,99]$. Suspensões coloidais de Au-NPs absorvem luz na região do visível, devido à ressonância de plasmão de superfície (surface plasmon resonance, SPR). Esta absorção ocorre a cerca de $520 \mathrm{~nm}$ (vermelho) [100-102], como se ilustra na figura 8; a sua intensidade aumenta com o tamanho das Au-NPs (para partículas com $\varnothing \geq 2-3 \mathrm{~nm}$ ), sem grande deslocamento do pico de absorção para partículas com diâmetro até cerca de $20 \mathrm{~nm}$ [103]; para partículas com $\varnothing<\approx 2 \mathrm{~nm}$, a banda de ressonância de plasmão de superfície não é identificável $[101,104]$. O aumento do tamanho das partículas ou a sua agregação leva a um alargamento e deslocamento do pico de absorção para valores de comprimento de onda $(\lambda)$ superiores; este deslocamento pode ser detectado por espectrofotometria de UV-visível ou inclusivamente observado à vista desarmada.



Figura 8 Espectro de absorvância obtido por espectrofotometria de UV-visível para uma suspensão coloidal de citrato/Au-NPs com diâmetro de cerca de $14 \mathrm{~nm} ; \lambda_{\max } \approx 516,5 \mathrm{~nm}$

que, presumivelmente, resultam do acoplamento oxidativo da ligação S-S.

\section{Estruturas Auto-Montadas envol- Vendo Nanopartículas de Ouro}

\section{Preparação de suspensões coloidais DE Au-NPS}

Nanopartículas são pequenos agregados de átomos cujas dimensões se encontram entre 1 e $100 \mathrm{~nm}[96,97]$. Apresentam propriedades ópticas,
Devido à elevada estabilidade, as Au-NPs têm atraído considerável interesse. O tamanho e propriedades são altamente dependentes das condições de preparação, encontrando-se descritos na literatura diversos métodos. Em geral, as nanopartículas de ouro são sintetizadas por redução química em solução de um sal de $\mathrm{Au}$ (III) (por ex. $\mathrm{KAuCl}_{4}, \mathrm{HAuCl}_{4}$ ou $\mathrm{AuCl}_{3}$ ) por um agente redutor (como citrato de sódio, borohidreto de sódio $\left(\mathrm{NaBH}_{4}\right)$ ou de potássio $\left.\left(\mathrm{KBH}_{4}\right)\right)$. A síntese pode ser efectuada tanto em fase homogénea, 
pelos métodos introduzidos por Turkevich (meio aquoso) [105] e refinado por outros autores $[106,107]$ e Kimura et al. [101] (meio orgânico), ou duas fases líquidas [108-111], inicialmente descrita por Brust et al. [112]. Neste caso, a transferência do $\mathrm{AuCl}_{4}^{-}$da fase aquosa para a orgânica usa, por exemplo, halogenetos de tetralquilamónio; a redução do $\mathrm{Au}$ (III) ocorre na fase orgânica por adição do redutor.

A acção de um estabilizador na solução de síntese é factor importante tanto na protecção (prevenindo a agregação) como no controle das propriedades das NPs. A interacção estabilizador/Au-NPs, pode ser diversa, desde simples adsorção física a interacções químicas mais fortes (adsorção química). As Au-NPs podem ser estabilizadas por iões citrato [86,99,103,106,113,114], polímeros [102,115], dendrímeros [116], tióis [100-102,104,107-114,117-119] e surfactantes [120]. Em certos casos, a espécie estabilizadora, que se adsorve na superfície das Au-NPs, pode ser o próprio redutor (como citrato de sódio) ou outra adicionada no passo de síntese (por ex. tióis). É ainda possível modificar a superfície das Au-NPs por reacções de substituição da espécie adsorvida num passo subsequente à síntese.

De uma maneira geral, a redução do $\mathrm{HAuCl}_{4}$ por citrato de sódio em água (redutor mais fraco e estabilizador fracamente adsorvido) leva à formação de partículas de maiores dimensões $(\varnothing \geq \approx 16 \mathrm{~nm})[86,103,105,106,114]$ do que as obtidas em metanol usando $\mathrm{NaBH}_{4}$ (redutor mais forte) e com adição de estabilizador - tiol $(\varnothing \geq 1$ nm) $[101,104,107,117]$. No entanto, o tamanho das Au-NPs pode ser controlado pela variação da razão agente redutor/Au ou estabilizador/Au $[103,104]$, especialmente quando a interacção estabilizador/Au-NPs é forte, como no caso dos tióis. Shiraishi et al. [102] e Yonezawa et al. [100] reportaram a síntese de Au-NPs por um método de redução por citrato de sódio modificado, em que o tiol (MPA= = ácido 3-mercaptopropiónico) foi adicionado durante a síntese, permitindo a obtenção de MPA/Au-NPs de dimensões reduzidas (8,8-2,2 nm), através da variação da razão MPA/
IAu (entre 0,1-3,0), à semelhança do reportado na redução por $\mathrm{NaBH}_{4}$ [101,104,107,117], tabela 1.

$<\mathrm{pK}_{\mathrm{a}}^{\mathrm{MPA}}$ ) e as repulsões electrostáticas entre partículas carregadas (grupo carboxílico do MPA desprotonado,

Tabela 1 Parâmetros experimentais e dimensões das NPs, obtidas por redução por citrato de sódio [100]

\begin{tabular}{ccccc}
\hline Razão S / $\mathrm{Au}$ & $\varnothing / \mathrm{nm}$ & $\begin{array}{c}\mathrm{n}\left(\mathrm{HAuCl}_{4}\right) \\
/ \mathrm{mmol}^{2}\end{array}$ & $\begin{array}{c}\mathrm{n}(\mathrm{MPA})^{£} \\
/ \mathrm{mmol}\end{array}$ & $\begin{array}{c}\mathrm{n}(\text { Citrato } \\
\text { Sódio })^{*} / \mathrm{mmol}\end{array}$ \\
\hline 0,1 & 8,8 & 5,8 & 0,58 & $1,7 \S$ \\
1,0 & 3,9 & & 5,8 & $1,7 \S$ \\
2,0 & 3,3 & & 11,6 & $1,7 \S$ \\
3,0 & 2,2 & & 17,4 & $1,7 \S$ \\
\hline
\end{tabular}

£ - $250 \mathrm{~mL} \mathrm{H} \mathrm{H}_{2} \mathrm{O} ; \S-25 \mathrm{~mL} ;{ }^{*}-2 \%(\mathrm{~m} / \mathrm{v}) \mathrm{H}_{2} \mathrm{O}$

De uma maneira geral, o tamanho das partículas diminui com o aumento da razão estabilizador/Au, tabela 1 , com adição rápida do redutor a baixa temperatura ou pelo uso de estabilizadores estericamente volumosos [116,121].

\section{Propriedades de Au-NPs PRotegl- DAS POR MONOCAMADAS}

Em sequência do desenvolvimento da auto-montagem de monocamadas em superfícies de ouro, surge a possibilidade de estabilização de Au-NPs por MC de alcanotióis. Em analogia com as superfícies de ouro, esta abordagem permite controlar propriedades que dependem das características do tiol [96], nomeadamente a reactividade e a dispersão das Au-NPs. Enquanto que Au-NPs sintetizadas em duas fases (tolueno/água) e modificadas com n-alcanotióis, e.g. o 1-butanotiol- BT/Au-NPs (BT = 1-butanotiol), apenas são dispersáveis em solventes não polares, como tolueno, pentano e clorofórmio [84]; NPs obtidas por redução com $\mathrm{NaBH}_{4}$ e estabilizadas por MSA (ácido mercaptosuccínico) não podem ser suspensas em solventes orgânicos, sendo-o facilmente em água [101]; Au-NPs estabilizadas por p-mercaptofenol, podem ser dispersas em alcóois, acetato de etilo e soluções fortemente alcalinas $(\mathrm{pH} \geq$ 13) [107]. Shiraishi et al. [102] também reportaram que Au-NPs, obtidas por redução por citrato e estabilizadas por MPA num único passo, podem ser suspensas em meio aquoso e reversivelmente agregadas/dispersas pela variação do $\mathrm{pH}$ da solução. Esta possibilidade, resultante da combinação entre as forças atractivas de van der Waals (ligações de hidrogénio entre grupos carboxílicos protonados em MPA/Au-NPs adjacentes, quando $\mathrm{pH}$
$\mathrm{pH}>\mathrm{pK}_{\mathrm{a}}^{\mathrm{MPA}}$, que confere carga negativa às MPA/Au-NPs), pode ser usada como indicador da efectiva modificação da superfície das Au-NPs. Permite a separação e purificação das NPs por simples variação do pH [101] e a sua montagem em estruturas através de interacções com outros substratos $[84-86,99,108,109,113]$. As Au-NPs estabilizadas por monocamadas (MC/Au-NPs) têm sido aplicadas na construção de estruturas bi- e tridimensionais (2D e 3D), em diferentes superfícies [84,108,118,119,122,123]. Diversas interacções são consideradas responsáveis pela imobilização selectiva, como forças de van der Waals [84], electrostáticas $[104,117,118]$ e ligações covalentes $[84,86,108,119,122,123]$. Na figura 9 ilustram-se algumas vias para a formação de tais estruturas: (a) interacção de $\mathrm{C}_{n}$-SH/Au-NPs com MC de $n$-alcanotiol através de forças de van der Waals [84]; (b) Au-NPs, estabilizadas por tióis contendo grupos funcionais terminais aniónicos/catiónicos, imobilizadas em superfícies modificadas por camadas de polielectrólitos ou MC contendo grupos catiónicos/ aniónicos livres [104,117,118]; (c-e) imobilização em substratos de Au, quando as Au-NPs [119,124] ou as superfícies $[78,86]$ são modificadas por MC contendo $\alpha, \omega$-alcanoditióis e (f) superfícies modificadas (por ex. vidro) contendo grupos - $\mathrm{SH}$ livres [122,125,126]. Stolarczyk et al. [84] reportaram que BT/Au-NPs ligadas ao eléctrodo através de monocamadas de 1,9-nonanoditiol (figura 9e), para além de originarem maior densidade de partículas e mais uniformemente distribuídas do que em MC de 1-decanotiol (adsorção simples através de interacções fracas de van der Waals), figura 9a, apresentam maior eficiência na transferência electrónica entre o eléctrodo e espécies electroactivas em solução. 


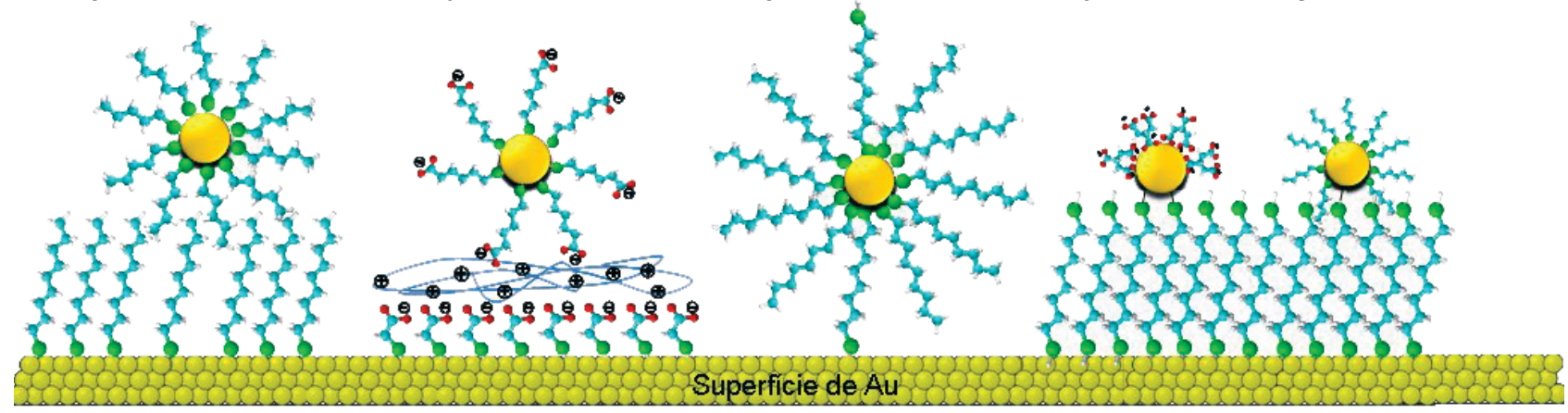

Figura 9 Representação esquemática de diferentes abordagens usadas para imobilização de Au-NPs em superfícies modificadas por MC auto-montadas $(a, b, d-f)$ ou não modificadas (c)

Stolarczyk et al. [84] reportaram que BT/Au-NPs ligadas ao eléctrodo através de monocamadas de 1,9-nonanoditiol (figura 9e), para além de originarem maior densidade de partículas e mais uniformemente distribuídas do que em MC de 1-decanotiol (adsorção simples através de interacções fracas de van der Waals), figura 9a, apresentam maior eficiência na transferência electrónica entre o eléctrodo e espécies electroactivas em solução.

É também possível a formação de estruturas 3D por adição de um $\alpha, \omega$ -alcanoditiol à suspensão coloidal de Au-NPs ou à solução de síntese das partículas. Verifica-se a interligação de Au-NPs através da formação de ligações Au-S entre os grupos tiol da molécula (espaçador ditiol) e partículas de Au [122], posteriormente imobilizáveis em superfícies de $\mathrm{Au}$ $[122,124]$. O mesmo objectivo é conseguido montando camadas sucessivas de ditiol e Au-NPs - substrato/ /(ditiol/Au-NPs) $)_{m}[78,122]$, figura 10.

\section{A TRANSFERÊNCIA ELECTRÓNICA EM SISTEMAS SUBSTRATO/ $/(\mathrm{MC} / \mathrm{Au}-\mathrm{NPs})_{m}$}

Neste tipo de sistemas, a transferência electrónica (TE) entre as Au-NPs e o substrato, para além de ser influenciada pela compacidade, organização da MC na superfície do eléctrodo e características do seu grupo terminal, depende da distribuição das NPs, da distância entre estes centros condutores e o substrato e da natureza da espécie electroactiva em solução $[84,86,122,127]$. A presença sobre as MCs ou em multicamadas ( $m$ camadas), facilita a TE entre espécies electroactivas em solução (por ex. $\left.\left[\mathrm{Fe}(\mathrm{CN})_{6}\right]^{4-},\left[\mathrm{Ru}\left(\mathrm{NH}_{3}\right)_{6}\right]^{3+}\right)$ e a superfície do eléctrodo, relativamente à $\mathrm{MC}$ simples [78,84,86,122]. Quando Au-NPs são imobilizadas em MC de ditiol em $\mathrm{Au}$, a TE entre o $\left[\mathrm{Fe}(\mathrm{CN})_{6}\right]^{4-} \mathrm{em}$ solução e a superfície do eléctrodo é afectada: aumenta, para Au-NPs $\approx 4$ $\mathrm{nm}$ (densidade superficial de BT/Au-NPs $\approx 50 \%$ sobre MC de 1,9-nonanoditiol; $t=1 \mathrm{~min}$.) [84] e não varia signifi- a



Figura 10 Formação de estruturas 3D contendo (a) Au-NPs interligadas via $\alpha, \omega$-alcanoditiol, em solução e imobilização em superfície de Au e (b) multicamadas de Au-NPs e $\alpha, \omega$-alcanoditiol em Au (substrato (Au)/(ditiol/Au-NPs) ${ }_{m}$ ) cativamente para Au-NPs de $\approx 17 \mathrm{~nm}$ (densidade superficial citrato/Au-NPs $\approx 2,56 \%$ sobre MCs de HS- $\mathrm{C}_{n}-\mathrm{SH}, n=$ $=6$ e $9 ; \mathrm{t} \approx 8 \mathrm{~min}$.) [86]. Estruturas 3D (por ex. sobre Au, vidro) envolvendo nanopartículas e ditióis podem apresentar comportamentos distintos desde (i) uma matriz de microeléctrodos onde ocorre difusão radial (forma sigmoidal dos voltamogramas cíclicos; camadas de difusão não sobrepostas) a (ii) um comportamento característico de difusão linear, em que duas situações são possíveis: existência de uma superfície metálica contínua ou uma matriz de microeléctrodos, com camadas de difusão sobrepostas, devido à elevada densidade de partículas metálicas na superfície do eléctrodo. Eléctrodos modificados por (1) Au-NPs ( $\approx 5 \mathrm{~nm}$ ) estabilizadas por $n$-alcanotiol e interligadas via reacção de substituição com 1,9-nonanoditiol (imobilizadas em superfícies de Au num arranjo 3D com espessura $\approx 100 \mathrm{~nm}$ ) [127], (2) estruturas formadas por citrato/Au-NPs $(\approx 12 \mathrm{~nm})$ e 2-mercaptoetilamina - MEA (até $m=$ 7 , sobre vidro modificado, com grupos tiol livres na interface com a solução) ou 1,6-hexanoditiol ( $m=3$, em Au) $[78,126]$, comportam-se como uma matriz de microeléctrodos com camadas de difusão não sobrepostas. No caso de multicamadas, com MEA para $m \geq 8$ e com 1,6-hexanoditiol para $m>$ 3 , ocorre difusão linear $[78,126]$.

Estruturas formadas por Au-NPs e ditióis (quando a camada exposta à solução é a de Au-NPs) sobre vidro modificado por grupos -SH não apresentam condutividade metálica (esperada para este tipo de materiais) [122]. Neste caso, a resistividade aumenta com o comprimento da cadeia 
alquilo do espaçador ditiol (de 6-7 para 1400-1600 $\Omega \mathrm{cm}$ com HS- $\mathrm{C}_{n}-\mathrm{SH}$, $n=6,12$ ) e diminui com o aumento da temperatura, comportamento que sugere a ocorrência de transporte de cargas individuais entre partículas adjacentes nestes filmes metálicos (com ilhas metálicas) descontínuos [122]. Au-NPs agregadas com ditiol em solução e depositadas, por compressão, em superfícies, como se ilustra na figura $10 \mathrm{a}$, apresentam um comportamento típico de semicondutores. A condutividade decresce com o aumento de $n$ no ditiol (entre 6,7 x $\times 10^{-6}$ para 1,5-pentanoditiol e 3,6 x $\times 10^{-7} \mathrm{~S} \mathrm{~cm}^{-1}$ para 1,6-hexanoditiol; $\varnothing_{\text {Au-NPs }} \approx 2 \mathrm{~nm}$ ) e aumenta com o tamanho das partículas $\left(1,3 \times 10^{-3} \mathrm{~S} \mathrm{~cm}^{-1}\right.$ para 1,12-dodecanoditiol; $\varnothing_{\text {Au-NPs }} \approx 8 \mathrm{~nm}$ ) [122]. Nas estruturas Au/(ditiol/Au-NPs) ${ }_{m}$, embora a TE possa ocorrer entre as Au-NPs, a que respeita às espécies electroactivas em solução apenas acontece na interface exposta Au-NPs/solução; a velocidade de TE aumenta após imobilização de Au-NPs (Au/(ditiol/Au-NPs) $)_{m}$ ) e diminui para a camada exposta de ditiol (Au/(ditiol/Au-NPs) ${ }_{m} /$ ditiol) [78].

\section{Comentário Final}

Com rigor, adequado detalhe e vasto suporte bibliográfico procurou caracterizar-se o estado actual do conhecimento sobre o tema em apreço. Relevando o significativo avanço científico atingido, tem de admitir-se que diversos aspectos fundamentais permanecem pouco claros, nomeadamente o mecanismo de adsorção dos alcanotióis em superfícies metálicas a partir de solução, o destino do hidrogénio do tiol durante a adsorção e a mobilidade superficial das moléculas adsorvidas. Métodos para o controle de defeitos nas MC e manipulação da composição à escala molecular, que incluem, nomeadamente, a adsorção sob um potencial aplicado e a formação de filmes finos orgânicos mistos (diferente comprimento de cadeia alquilo e grupos terminais), carecem de mais desenvolvimento. Mais investigação, relativa ao processo de deposição, como o efeito do potencial aplicado, dependência do tempo, da concentração de tiol (ou fracção molar dos componentes), estado do substrato, para além da reprodutibilidade (das suas propriedades, estrutura e composição), são necessários para um mais amplo esclarecimento e compreensão fenomenológica. O controle da composição de MCs mistas permite a modelação das propriedades das superfícies modificadas, por exemplo para interacção com biomoléculas (muito relevantes na compreensão de sistemas biológicos e biocompatibilidade) e deposição selectiva de metais em domínios específicos. Embora a preparação de MC mistas por adsorção, a partir de solução, com composição previsível e reprodutível seja difícil, se não impossível, uma abordagem aparentemente promissora é a formação de MC mistas sob potencial aplicado. O desenvolvimento de novos modelos compatíveis com a formação de MC complexas (tióis contendo grupos funcionais volumosos e geometrias complexas, substratos com geometrias não-planas), importantes para aplicações tanto em biologia como nas nanociências, é também desejável. $O$ alargamento das classes de moléculas para a formação de MC e os materiais do substrato poderão constituir novas abordagens. A aproximação da complexidade das MC aos sistemas dinâmicos é outro desafio que se coloca.

A síntese de Au-NPs estabilizadas por monocamadas ampliou a disponibilidade de materiais funcionalizados. No entanto, o efeito complexo da dimensão das NPs, distribuição de tamanho, topologia, constituição, natureza das moléculas estabilizadoras, estado de carga das partículas, meio envolvente e ambiente dieléctrico não está ainda suficientemente compreendido, requerendo estudos mais extensivos e sistemáticos permitindo evoluir para a aplicação em electrónica, óptica, catálise, reconhecimento químico e em biologia. A formação de estruturas contendo MC e Au-NPs em superfícies modificadas ou não, apresenta também algumas fragilidades, nomeadamente, a dificuldade de obter camadas de NPs organizadas e uniformemente distribuídas, o controle da distância e interacção entre partículas e entre estas e o substrato, a modelação das propriedades condutoras e do mecanismo de transferência electrónicas nessas estruturas; constitui, assim, mais uma vasta área de investigação prioritária.

\section{Agradecimentos}

V.C. Ferreira expressa o seu agradecimento à Fundação para a Ciência e a Tecnologia pelo apoio financeiro (SFRH/BD/30585/2006).

\section{Notas}

${ }^{1}$ A estrutura $(\sqrt{3} x \sqrt{3}) \mathrm{R} 30^{\circ}$ refere-se ao alinhamento dos átomos adsorvidos em $\mathrm{Au}(111)$ com uma rotação de $30^{\circ}$ relativamente à célula unitária da superfície de $\mathrm{Au}(111)$, apresentando um espaçamento entre o átomo mais próximo e o imediatamente a seguir de 0,49 e 0,89 nm, respectivamente.

${ }^{2}$ A reconstrução $(\sqrt{ } 3 \times 22)$ do $A u(111)$ consiste num arranjo dos átomos da superfície que conduz a que a cada a $23^{\circ}$ um átomo esteja sobreposto com o da camada subjacente.

${ }^{3} \mathrm{Na}$ superfície $\mathrm{Au}(110)$, a estrutura $c(2 \times 2)$ indica que o espaçamento entre os átomos adsorvidos é 2 vezes a distância entre os de Au na célula unitária da superfície.

\section{REFERÊNCIAS}

[1] M.D. Porter, T.B. Bright, D.L. Allara, C.E.D. Chidsey, Journal of the American Chemical Society 109 (1987) 3559-3568.

[2] P.E. Laibinis, G.M. Whitesides, Journal of the American Chemical Society 114 (1992) 9022-9028.

[3] C. Schonenberger, J. Jorritsma, J.A.M. Sondag-Huethorst, L.G.J. Fokkink, Journal of Physical Chemistry 99 (1995) 3259-3271.

[4] N. Camillone III, T.Y.B. Leung, P. Schwartz, P. Eisenberg, G. Scoles, Langmuir 12 (1996) 2737-2746.

[5] T.Y.B. Leung, M.C. Gerstenberg, D.J. Lavrich, G. Scoles, Langmuir 16 (2000) 549-561 (e referências aí citadas).

[6] C.E.D. Chidsey, D.N. Loiacono, Langmuir 6 (1990) 682-691.

[7] D.-F. Yang, C.P. Wilde, M. Morin, Langmuir 13 (1997) 243-249.

[8] D.-F. Yang, C.P. Wilde, M. Morin, Langmuir 12 (1996) 6570-6577.

[9] M.M. Walczak, D.D. Popenoe, R.S. Deinhammer, B.D. Lamp, C. Chung, M.D. Porter, Langmuir 7 (1991) 2687-2693 .

[10] C.-J. Zhong, J. Zak, M.D. Porter, Journal of Electroanalytical Chemistry $\mathbf{4 2 1}$ (1997) 9-13. 
[11] R.G. Nuzzo, L.H. Dubois, D.L. Allara, Journal of the American Chemical Society 112 (1990) 558-569.

[12] S.J. Stranik, A.N. Parikh, Y.-T. Tao, D.L. Allara, P.S. Weiss, Journal of Physical Chemistry 98 (1994) 7636-7646.

[13] T. Nakanishi, B. Ohtani, K. Uosaki, Journal of Physical Chemistry B 102 (1998) 1571-1577.

[14] G. Meshulam, N. Rosenberg, A. Caster, L. Burstein, M. Gozin, S. Richter, Small 1 (2005) 848-851.

[15] U.K. Sur, R. Subramanian, V. Lahshminayanan, Journal of Colloid and Interface Science 266 (2003) 175-182.

[16] P. Kohli, K.K. Taylor, J.J. Harris, G.J. Blanchard, Journal of the American Chemical Society 120 (1998) 11962$-11968$.

[17] S.W. Joo, S.W. Han, K. Kim, Langmuir 16 (2000) 5391-5396.

[18] S.W. Joo, S.W. Han, K. Kim, Journal of Physical Chemistry B 104 (2000) 6218$-6224$.

[19] S.W. Joo, S.W. Han, K. Kim, Journal of Physical Chemistry B 103 (1999) 10831-10837.

[20] T. Wadayama, M. Oishi, Surface Science 600 (2006) 4352-4356.

[21] M.M. Walczak, C.A. Alves, B.D. Lamp, M.D. Porter, Journal of Electroanalytical Chemistry 396 (1995) 103-114.

[22] M. Brust, P.M. Blass, A.J. Bard, Langmuir 13 (1997) 5602-5607.

[23] W. Deng, L. Yang, D. Fujita, H. Nejoh, C. Bai, Applied Physics A: Materials Science \& Processing 71 (2000) 639$-642$.

[24] P.E. Laibinis, M.A. Fox, J.P. Folkers, G.M. Whitesides, Langmuir 7 (1991) 3167-3173.

[25] C.D. Bain, E.B. Troughton, Y.-T. Tao, J. Evall, G.M. Whitesides, R.G. Nuzzo, Journal of the American Chemical Society 111 (1989) 321-335.

[26] C.D. Bain, H.A. Biebuyck, G.M. Whitesides, Langmuir 5 (1989) 723-727.

[27] H. Rieley, G.K. Kendall, F.W. Zemacael, T.L. Smith, S. Yang, Langmuir 14 (1998) 5147-5153.

[28] D. Qu, K. Uosaki, Journal of Physical Chemistry B 110 (2006) 17570-17577.

[29] T. Ohgi, H.-Y. Sheng, Z.-C. Dong, H. Nejoh, D. Fujita, Applied Physics Letters 79 (2001) 2453-2455.

[30] E. Delamarche, B. Michel, H. Kang, C. Gerber, Langmuir 10 (1994) 4103-4108 .

[31] F. Schreiber, A. Eberhardt, T.Y.B. Leung, P. Schwartz, S.M. Wetterer, D.J. Lavrich, L. Berman, P. Fenter, P. Eisen- berger, G. Scoles, Physical Review $B$ 57 (1998) 12474-12481.

[32] M.G. Samant, C.A. Brown, J.G. Gordon II, Langmuir 7 (1991) 437-439.

[33] P. Fenter, P. Eisenberger, K.S. Liang, Physical Review Letters 70 (1993) 2447-2450.

[34] L. Strong, G.M. Whitesides, Langmuir 4 (1988) 546-558.

[35] N. Camillone III, P. Eisenberg, T.Y.B. Leung, P. Schwartz, G. Scoles, Journal of Chemical Physics 101 (1994) 11031-11036 .

[36] N. Camillone III, C.E.D. Chidsey, G.-Y. Liu, G. Scoles, Journal of Chemical Physics 98 (1993) 4234-4245.

[37] C.E.D. Chidsey, G.-Y. Liu, P. Rowntree, G. Scoles, Journal of Chemical Physics 91 (1989) 4421-4423.

[38] H.O. Finklea, S. Avery, M. Lynch, Langmuir 3 (1987) 409-413.

[39] M.J. Esplandiu, H. Hagenstrom, Solid State Ionics 150 (2002) 39-52.

[40] T. Sumi, K. Uosaki, Journal of Physical Chemistry B 108 (2004) 6422-6428.

[41] C.-J. Zhong, M.D. Porter, Journal of Electroanalytical Chemistry 425 (1997) 147-153.

[42] T. Sumi, H. Wano, K. Uosaki, Journal of Electroanalytical Chemistry 550-551 (2003) 321-325.

[43] T. Arakawa, D. Hobara, M. Yamamoto, T. Kakiuchi, Electrochemistry Communications 7 (2007) 848-852.

[44] S.-I. Imabayachi, D. Hobara, T. Kakiuchi, Langmuir 13 (1997) 4502-4504.

[45] C.A. Widrig, C. Chung, M.D. Porter, Journal of Electroanalytical Chemistry 310 (1991) 335-359.

[46] T. Kawaguchi, H. Yasuda, K. Shimazu, Langmuir 16 (2000) 9830-9840.

[47] M.L. Carot, M.J. Esplandiu, F.P. Cometto, E.M. Patrito, V.A. Macagno, Journal of Electroanalytical Chemistry 579 (2005) 13-23.

[48] M.J. Esplandiu, M.L. Carot, F. Cometto, V. Macagno, E.M. Patrito, Surface Science 600 (2006) 155-172.

[49] J.M. Campina, A. Martins, F. Silva, Journal of Physical Chemistry C 111 (2007) 5351-5362.

[50] J.A.M. Sondag-Huethorst, L.G.J. Fokkink, Langmuir 11 (1995) 2237-2241.

[51] T.W. Schneider, D.A. Buttry, Journal of the American Chemical Society 115 (1993) 12391-12397.

[52] D. Qu, M. Morin, Journal of Electroanalytical Chemistry 517 (2001) 45-53.

[53] C.A. McDermott, M.T. McDermott, J.-B. Green, M.D. Porter, Journal of Physical Chemistry 99 (1995) 13257-13267.
[54] N. Vandamme, J. Snauwaert, E. Janssens, E. Vandeweert, P. Lievens, C.V. Haesendonck, Surface Science $\mathbf{5 5 8}$ (2004) 57-64.

[55] T. Ohgi, H.-Y. Sheng, H. Nejoh, Applied Surface Science 130-132 (1998) 919-924.

[56] J. Liang, L.G. Rosa, G. Scoles, Journal of Physical Chemistry C 111 (2007) 17275-17284.

[57] R.L. McCarley, Y.-T. Kim, A.J. Bard, Journal of Physical Chemistry 97 (1993) 211-215.

[58] G.E. Poirier, M.J. Tarlov, H.E. Rushmeier, Langmuir 10 (1994) 3383-3386.

[59] G.E. Poirier, M.J. Tarlov, Langmuir 10 (1994) 2853-2856.

[60] C. Schonenberger, J.A.M. SondagHuethoorst, J. Jorritsma, L.G.J. Fokkink, Langmuir 10 (1994) 611-614.

[61] D.J. Fuchs, P.S. Weiss, Nanotechnology18(2007)044021 (doi:10.1088/09574484/18/4/044021).

[62] C.A. Widrig, C.A. Alves, M.D. Porter, Journal of the American Chemical Society 113 (1991) 2805-2810.

[63] T. Nakamura, H. Kondoh, M. Matsumoto, H. Nozoye, Langmuir 12 (1996) 5977-5979.

[64] W. Jiang, N. Zhitenev, Z. Bao, H. Meng, D. Abusch-Magder, D. Tennant, E. Garfunkel, Langmuir 21 (2005) 8751-8757.

[65] S.-S. Wong, M.D. Porter, Journal of Electroanalytical Chemistry 485 (2000) 135-143.

[66] D.M. Kolb, Progress in Surface Science 51 (1996) 109-173.

[67] W. Mar, M.L. Klein, Langmuir 10 (1994) 188-196.

[68] A.-S. Duwez, L.M. Yu, J. Ruga, J.-J. Pireaux, J. Delhalle, Thin Solid Films 327-329 (1998) 156-160.

[69] L.H. Dubois, B.R. Zegarski, R.G. Nuzzo, Journal of Chemical Physics 98 (1993) 678-688.

[70] Y.-T. Kim, R.L. McCarley, A.J. Bard, Langmuir 9 (1993) 1941-1944.

[71] A.S. Viana, L.M. Abrantes, G. Jin, S. Floate, R.J. Nichols, M. Kalaji, Physical Chemistry Chemical Physics 3 (2001) 3411-3419.

[72] W.H. Mulder, J.J. Calvente, R. Andreu, Langmuir 17 (2001) 3273-3280.

[73] C. Schulz, B. Speiser, Journal of Electroanalytical Chemistry 354 (1993) 255-271.

[74] H. Oevering, M.N. Paddon-Row, M. Heppener, A.M. Oliver, E. Cotsaris, J.W. Verhoeven, N.S. Hush, Journal of the American Chemical Society 109 (1987) 3258-3269. 
[75] S.J. Stranick, S.V. Atre, A.N. Parikh, M.C. Wood, D.L. Allara, N. Winograd, P.S. Weiss, Nanotechnology 7 (1996) 438-442.

[76] J.P. Folkers, P.E. Laibinis, G.M. Whitesides, Journal of Physical Chemistry 98 (1994) 563-571.

[77] P.H. Phong, V.V. Sokolov, N. Nishi, M. Yamamoto, T. Kakiuchi, Journal of Electroanalytical Chemistry 600 (2007) 35-44.

[78] M. Lu, X.H. Li, B.Z. Yu, H.L. Li, Journal of Colloid and Interface Science 248 (2002) 376-382.

[79] S. Kohale, S.M. Molina, B.L. Weeks, R. Khare, L.J. Hope-Weeks, Langmuir 23 (2007) 1258-1263.

[80] K. Kobayashi, T. Horiuchi, H. Yamada, K. Matsushige, Thin Solid Films 331 (1998) 210-215.

[81] G.E. Poirier, Langmuir 15 (1999) 1167$-1175$.

[82] G.E. Poirier, Chemical Reviews 97 (1997) 1117-1127.

[83] J. Zheng, Y. Zhou, X. Li, Y. Ji, T. Lu, R. Gu, Langmuir 19 (2003) 632-636.

[84] K. Stolarczyk, R. Bilewicz, Electrochimica Acta 51 (2006) 2358-2365.

[85] Y. Sakotsubo, T. Ohgi, D. Fujita, Y. Ootuka, Physica E 29 (2005) 601-605.

[86] M. Yang, Z. Zhang, Electrochimica Acta 49 (2004) 5089-5095.

[87] B. Boer, M.M. Frank, W. Jiang, E. Garfunkel, Z. Bao, Langmuir 20 (2004) 1539-1542.

[88] T. Aqua, H. Cohen, A. Vilan, R. Naaman, Journal of Physical Chemistry C 111 (2007) 16313-16318.

[89] T. Ohgi, H.-Y. Sheng, Z.-C. Dong, H. Nejoh, Surface Science 442 (1999) 277-282.

[90] T. Ohgi, D. Fujita, W. Deng, Z.-C. Dong, H. Nejoh, Surface Science 493 (2001) 453-459.

[91] M.J. Tarlov, Langmuir 8 (1992) 80-89.

[92] M.J. Esplandiu, P.-L. Noeske, Applied Surface Science 199 (2002) 166-182.

[93] H. Rieley, N.J. Price, R.G. White, R.I.R. Blyth, A.W. Robinson, Surface Science 331-333 (1995)189-195.

[94] Y. Li, J. Huang, R.T. Mclver, J.C. Hem- minger, Journal of the American Chemical Society 114 (1992) 2428-2432.

[95] U. Weckernmann, S. Mittler, K. Naumann, R.A. Fischer, Langmuir 18 (2002) 5479-5486.

[96] Y.-S. Shon, "Metal Nanoparticles Protected with Monolayers: Synthetic Methods", in J.A. Schwarz; C.I. Contescu; K. Putyera (ed.), Dekker Encyclopedia of Nanoscience and Nanotechnology, Marcel Dekker: New York (2004) 1-11.

[97] J.H. Fendler, Chemistry of Materials 8 (1996) 1616-1624.

[98] C.M. Welch, R.G. Compton, Analytical and Bioanalytical Chemistry 384 (2006) 601-619.

[99] I.-I.S. Lim, C.-J. Zhong, Gold Bulletin 40 (2006) 59-66.

[100] T. Yonezawa, T. Kunitake, Colloids and Surfaces A: Physicochemical and Engineering Aspects 149 (1999) 193$-199$.

[101] S. Chen, K. Kimura, Langmuir 15 (1999) 1075-1082.

[102] Y. Shiraishi, D. Arakawa, N. Toshima, European Physical Journal E 8 (2002) 377-383.

[103] J. Kimling, M. Maier, B. Okenve, V. Kotaidis, H. Ballot, A. Plech, Journal of Physical Chemistry B 110 (2006) 15700-15707.

[104] M. Chirea, V. García-Morales, J.A. Manzanares, C. Pereira, R. Gulaboski, F. Silva, Journal of Physical Chemistry B 109 (2005) 21808-21817.

[105] J. Turkevich, P.C. Stevenson, J. Hiller, Discussions of the Faraday Society 11 (1951) 55-74.

[106] B.V. Enustun, J. Turkevich, Journal of the American Chemical Society $\mathbf{8 5}$ (1963) 3317-3328.

[107] M. Brust, J. Fink, D.J. Schiffrin, C. Kiely, Journal of the Chemical Society, Chemical Communications (1994) 1655-1656.

[108] K. Stolarczyk, R. Bilewicz, Electroanalysis 16 (2004) 1609-1615.

[109] M.J. Hostetler, J.J. Stokes, R.W. Murray, Langmuir 12 (1996) 3604-3612.

[110] D.V. Leff, P.C. Ohara, J.R. Heath, W.M. Gelbart, Journal of Physical
Chemistry 99 (1995) 7036-7041.

[111] S.Y. Heriot, J.-M. Pedrosa, L. Camacho, T.H. Richardson, Materials Science and Engineering C 26 (2006) 154-162.

[112] M. Brust, M. Walker, D. Bethel, D.J. Schiffrin, R. Whyman, Journal of the Chemical Society, Chemical Communications (1994) 801-802.

[113] Z.P. Li, X.R. Duan, C.H. Liu, B.A. Du, Analytical Biochemistry 351 (2006) 18-25 .

[114] M. Giersig, P. Mulvaney, Langmuir 9 (1993) 3408-3413.

[115] A. Mayer, M. Antonietti, Colloid and Polymer Science 276 (1998) 769-779.

[116] C.S. Love, V. Chechik, D.K. Smith, C. Brennan, Journal of Materials Chemistry 14 (2004) 919-923.

[117] M. Chirea, C.M. Pereira, F. Silva, Journal of Physical Chemistry C 111 (2007) 9255-9266.

[118] H.A. Santos, M. Chirea, V. GarciaMorales, F. Silva, J.A. Manzanares, K. Kontturi, Journal of Physical Chemistry B 109 (2005) 20105-20114.

[119] S. Chen, Journal of Physical Chemistry B 104 (2000) 663-667 (e referências aí citadas).

[121] N. Zheng, J. Fan, G.D. Stucky, Journal of the American Chemical Society 128 (2006) 6550-6551.

[122] D. Bethel, M. Brust, D.J. Schiffrin, C. Kiely, Journal of Electroanalytical Chemistry 409 (1996) 137-143.

[123] E.W.L. Chan, L. Yu, Langmuir 18 (2002) 311-313.

[124] B. Su, H.H. Girault, Journal of Physical Chemistry B 109 (2005) 23925-23929 .

[125] K.C. Grabar, P.C. Smith, M.D. Musick, J.A. Davis, D.G. Walter, M.A. Jackson, A.P. Guthrie, M.J. Natan, Journal of the American Chemical Society 118 (1996) 1148-1153.

[126] M.D. Musick, D.J. Peña, S.L. Botsko, T.M. McEvoy, J.N. Richardson, M.J. Natan, Langmuir 15 (1999) 844-850.

[127] C.J. Zhong, W.X. Zheng, F.L. Leibowitz, Electrochemistry Communications 1 (1999) 72-77. 